Article

\title{
Droplet Flow Assisted Electrocatalytic Oxidation of Selected Alcohols under Ambient Condition
}

\author{
Mohammed A. Suliman ${ }^{1}$ (D), Khaled M. Al Aqad ${ }^{1}$ and Chanbasha Basheer $1,2, * \mathbb{D}$ \\ 1 Department of Chemistry, King Fahd University of Petroleum and Minerals, Dhahran 31261, Saudi Arabia; \\ g201403100@kfupm.edu.sa (M.A.S.); g201310930@kfupm.edu.sa (K.M.A.A.) \\ 2 Interdisciplinary Research Centre for Membranes and Water Security, King Fahd University of Petroleum and \\ Minerals, Dhahran 31261, Saudi Arabia \\ * Correspondence: cbasheer@kfupm.edu.sa
}

Citation: Suliman, M.A.; Al Aqad, K.M.; Basheer, C. Droplet Flow Assisted Electrocatalytic Oxidation of Selected Alcohols under Ambient Condition. Molecules 2022, 27, 382. https://doi.org/10.3390/molecules 27020382

Academic Editor: César Augusto Correia de Sequeira

Received: 1 December 2021

Accepted: 4 January 2022

Published: 7 January 2022

Publisher's Note: MDPI stays neutral with regard to jurisdictional claims in published maps and institutional affiliations.

Copyright: (C) 2022 by the authors. Licensee MDPI, Basel, Switzerland. This article is an open access article distributed under the terms and conditions of the Creative Commons Attribution (CC BY) license (https:// creativecommons.org/licenses/by/ $4.0 /)$.

\begin{abstract}
This study reports using a droplet flow assisted mechanism to enhance the electrocatalytic oxidation of benzyl alcohol, 2-phenoxyethanol, and hydroxymethylfurfural at room temperature. Cobalt phosphide (CoP) was employed as an active electrocatalyst to promote the oxidation of each of the individual substrates. Surface analysis of the CoP electrocatalyst using scanning electron microscopy (SEM), energy-dispersive X-ray spectroscopy (EDS), X-ray photoelectron spectroscopy (XPS), as well as electrochemical characterization, revealed that it had excellent catalytic activity for each of the substrates studied. The combined droplet flow with the continuous flow electrochemical oxidation approach significantly enhanced the conversion and selectivity of the transformation reactions. The results of this investigation show that at an electrolysis potential of $1.3 \mathrm{~V}$ and ambient conditions, both the selectivity and yield of aldehyde from substrate conversion can reach $97.0 \%$.
\end{abstract}

Keywords: electrosynthesis; oxidation; alcohols; undivided cell; droplet assisted; electrocatalyst

\section{Introduction}

Electrochemical organic synthesis is one of the most promising organic synthetic tools available, potentially providing a more sustainable and environmentally friendly pathway to produce a wide range of chemical compounds. This is because it eliminates chemical waste by avoiding chemical oxidants and reductants, which is typical of the conventional chemical synthesis approach, and it can operate at mild reaction conditions [1]. More importantly, this synthesis protocol allows for a simple selective transformation of a substrate into useful intermediates or products with high functional group tolerance using only electricity [2]. In this synthesis approach, the applied potential and current to the reaction system can be easily controlled to regulate the redox reactions at the electrode interface [3]. To achieve selective transformation, a "controlled potential" higher than the substrate's redox potential must be supplied to the electrode to initiate the required chemical reaction.

Carbonyl molecules, such as ketones and aldehydes play key roles in synthetic organic chemistry due to their widespread use as precursors in the pharmaceutical and chemical industries [4]. In the classical chemical oxidation approach, alcohols are often oxidized to aldehydes or ketones in the presence of oxidants such as bromate, chromate, or manganates. However, the hazardous nature of these oxidants, and their likelihood of contaminating the target intermediates, has served as a significant drawback affecting this transformation approach. It has also been challenging to use these oxidants for the oxidation of a wide range of alcohols [5]. The electrochemical oxidation approach was recently advanced as a simple and highly efficient pathway for the selective oxidation of alcohols to primary intermediates. This method offers an appealing alternative to the classical approach. It does not require a chemical oxidant and only generates hydrogen as a by-product of the reaction without product contamination [6]. 
The published literature has widely explored the direct electrochemical selective oxidation of alcohols to aldehydes or ketones. Most of the documented studies have explored the use of noble metals as catalytic electrodes, such as $\mathrm{Ru}$ [6], and $\mathrm{Pt}$ [7], in various electrochemical cell configurations, including batch mode [7,8] and continuous flow setup [6]. Furthermore, most of these investigations reported moderate yield and selectivity with extended reaction time for the target aldehydes and ketones. Based on our findings, we believe that combining a microdroplet flow reaction with a continuous flow electrochemical cell should provide a highly efficient and rapid pathway for the selective oxidation of alcohols in the aqueous medium. Over the years, microdroplet flow chemistry has proven to be an important tool in speeding up reaction kinetics and for high throughput applications [6]. These unique characteristics of microdroplet reaction stem from its interfacial features related to its enormous surface-area-to-volume ratio, allowing it to offer a faster reaction rate than the bulk flow counterpart [8,9]. Droplets provide a confined, high-surface-area for chemical reactions, enhancing conversion and selectivity. Droplet-assisted reaction mechanisms are well-known, and several pieces of literature have already been discussed in detail $[10,11]$. Several reports have attributed this fast reaction rate to be due to the inherent interfacial properties that includes [9,12]: reagent (s) confinement $[13,14]$, partial solvation [9,15-17], pH extremes [18,19], and ordered molecule orientation [20-24]. A1though most previous research on reaction acceleration with microdroplets is often carried out in organic solvents, aqueous microdroplet reactions are rarely reported.

Over the years, metallic phosphide has evolved as a highly efficient electrocatalyst for oxidation reactions due to its high reactivity in an aqueous medium [25]. These transition metal species facilitate the deployment of oxyhydroxide species in an aqueous medium that has demonstrated excellent catalytic activity and effectiveness in the electrochemical oxidation reaction [26]. Cobalt phosphide (CoP) is highly sought as an active electrocatalyst among these transition metal species due to its ease of preparation. Phosphorus (P) has a lower electronegativity than sulfur, nitrogen, and oxygen $[27,28]$. It can, however, aid in the formation of oxides, hydroxides, and active phosphate centers on the catalyst surface, resulting in improved electrochemical performance. Even though the electrochemical oxidation active sites are only found on the catalyst's surface atoms, such reported thick or bulk cobalt phosphide nanostructures suffer from low utilization and exposure of the active sites, limiting their electrochemical activities. As a result, further improvement of the electrochemical oxidation performance of cobalt phosphide is still needed.

Applying the microdroplet flow-continuous flow electrochemical technique, this study investigated the selective oxidation of selected alcohols (benzyl alcohol, 2-phenoxyethanol, and Hydroxymethylfurfural (HMF) for the first time using a modified continuous electrochemical reactor that incorporates a microdroplet flow component. Moreover, CoP on the nickel foam (CoP@NiF) synthesized by the electrodeposition method was employed as the catalytic electrode. Furthermore, several potentials were tuned and optimized to achieve the highest yield and selectivity for the target aldehyde in the shortest period.

\section{Results and Discussion}

The particles of cobalt phosphide were synthesized by an electrodeposition technique using a potentiostat. A three-electrode system was employed, in which the nickel foam serves as a working electrode. The highly conductive Ni foam allows the continuous transfer of electrons across its entire structure, initializing the useful reduction of cobalt (II) ions and dihydrogen phosphate ions to give a net reaction to produce cobalt phosphide [29].

The structural details of bare nickel foam (NiF) and modified CoP@NiF were investigated using scanning electron microscopy (SEM). As illustrated (Figure 1a-c), the structure of bare nickel foam was retained while the surface became rougher in the modified CoP (Figure 1d). Low and high magnification of CoP@NiF showed the surface become dense and entirely covered by the CoP particles (Figure 1e,f). The energy-dispersive X-ray spectroscopy (EDS) elemental mapping confirmed the homogenous distribution of Co and $\mathrm{P}$ on NiF (Figure 2a-d). 


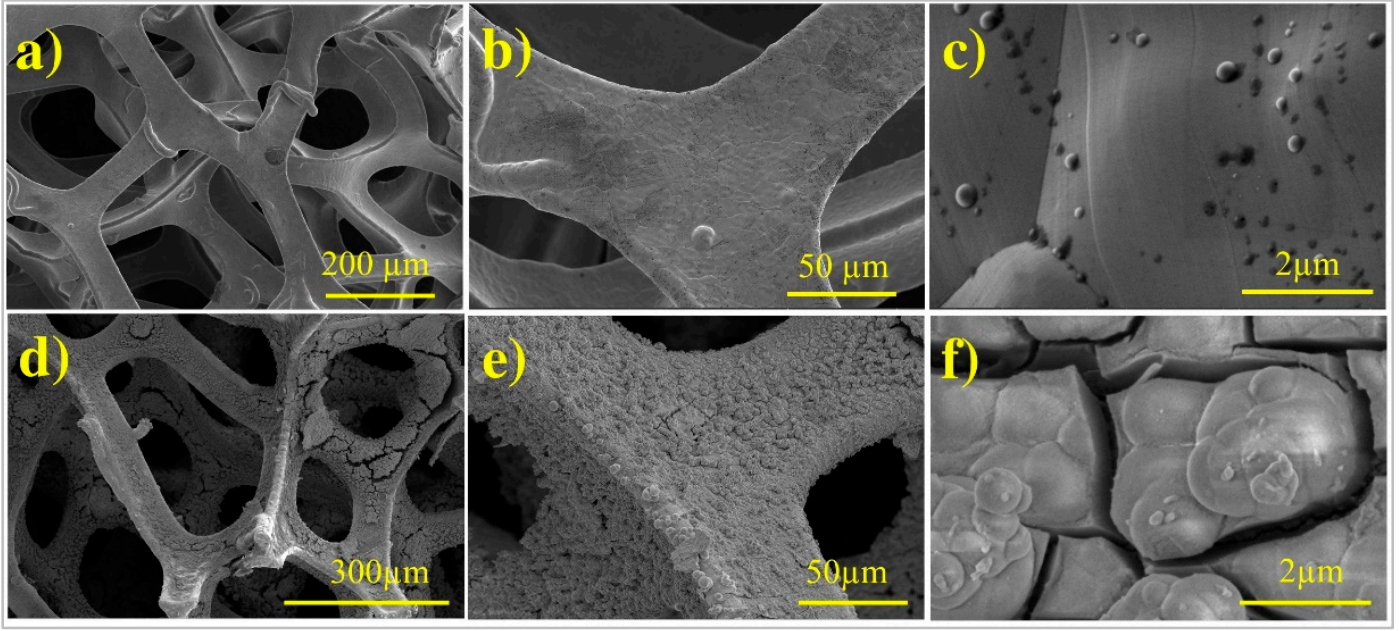

Figure 1. (a-c) low magnification SEM of bare $\mathrm{NiF},(\mathbf{d}-\mathbf{f})$ Low and high magnification SEM of CoP@NiF.

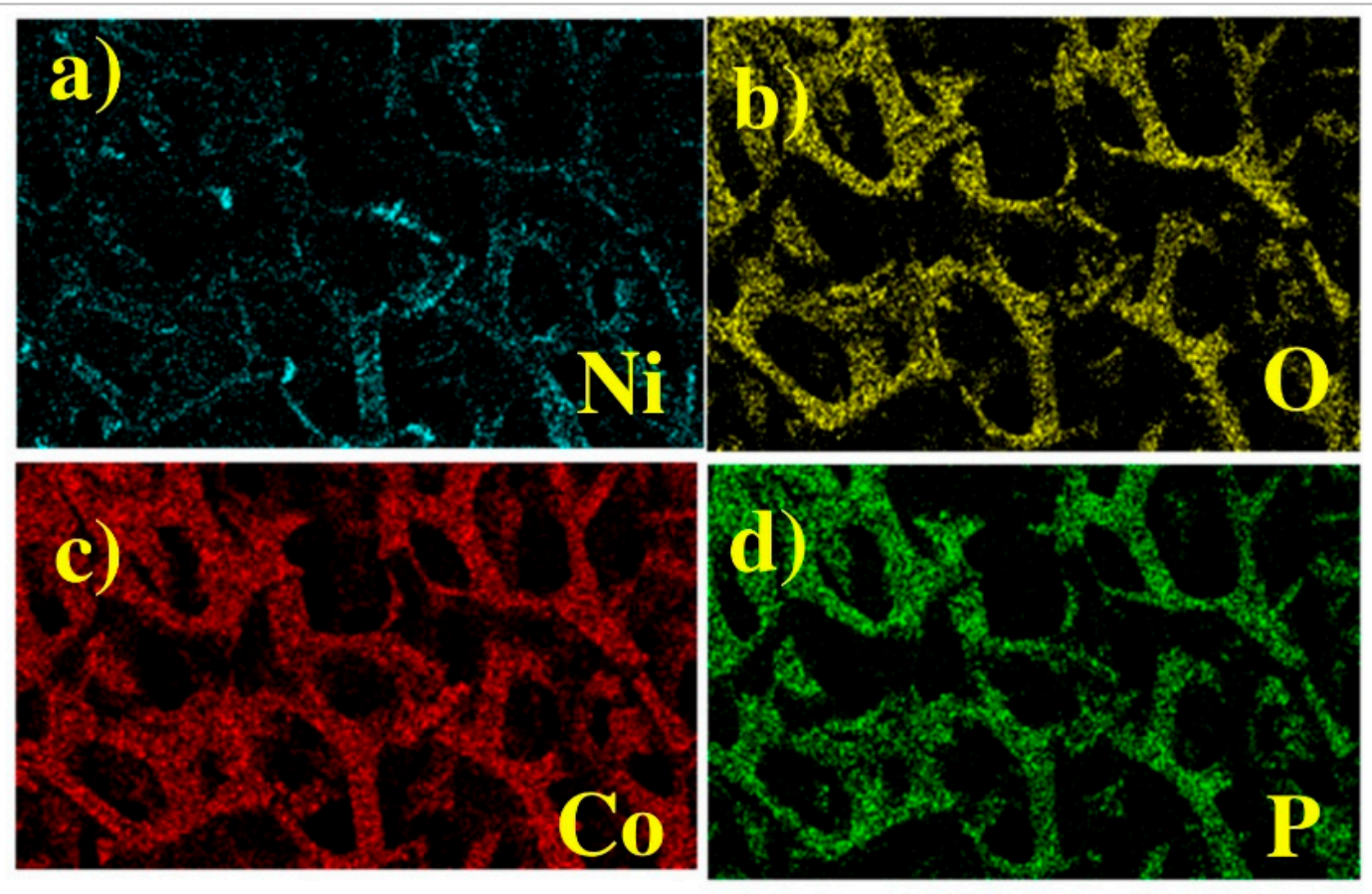

Figure 2. (a-d) the element mapping of $\mathrm{Ni}, \mathrm{O}, \mathrm{Co}$, and $\mathrm{P}$, respectively.

The surface chemical state of $\mathrm{CoP} @ \mathrm{NiF}$ is investigated using XPS. The survey spectra of CoP@NiF (Figure 3a) show that Co, P, Ni, and O elements coexist in the electrocatalyst. This was completely consistent with the EDX results. The binding energies (BEs) 781.10 $\left(2 \mathrm{p}_{3 / 2}\right)$ and $795.59\left(2 \mathrm{p}_{5 / 2}\right) \mathrm{eV}$ are ascribed to the binding energies Co $2 \mathrm{p}_{3 / 2}$ and Co $2 \mathrm{p}_{1 / 2}$ in CoP, respectively whereas the BEs 779.6 and $795.1 \mathrm{eV}$ are attributed to $\left(2 \mathrm{p}_{3 / 2}\right)$ and $\left(2 \mathrm{p}_{5 / 2}\right)$ [30]. Satellite peaks are the two remaining deconvoluted peaks, found at $786.54 \mathrm{eV}$ and $803.74 \mathrm{eV}$. Furthermore, the high-resolution XPS spectra of P 2p core levels can be deconvolved into three peaks, respectively positioned at $129.5 \mathrm{eV}$ for $\mathrm{P} 2 \mathrm{p}_{3 / 2}, 130.7 \mathrm{eV}$ for $\mathrm{P} 2 \mathrm{p}_{1 / 2}$, and $133.58 \mathrm{eV}$ for oxidized $\mathrm{P}$ species. The phosphate is represented by a wide peak at $135.4 \mathrm{eV}$, indicating surface oxidation [31,32]. The peaks at 781.2 and $134.4 \mathrm{eV}$ are attributed to oxidized Co and P species formed by the surface oxidation of CoP. It is proposed that the peaks at $780.4 \mathrm{eV}$ and $133.5 \mathrm{eV}$ develop as a result of the unavoidable interaction between the CoP surface and oxygen. The high-resolution $\mathrm{C}$ spectra of $\mathrm{O} 1 \mathrm{~s}$ 
supports the findings, which can be deconvoluted into three peaks of $\mathrm{P}-\mathrm{O}(533.2 \mathrm{eV}), \mathrm{C}-\mathrm{O}$ $(531.9 \mathrm{eV})$, and Co-O (531.3 eV).

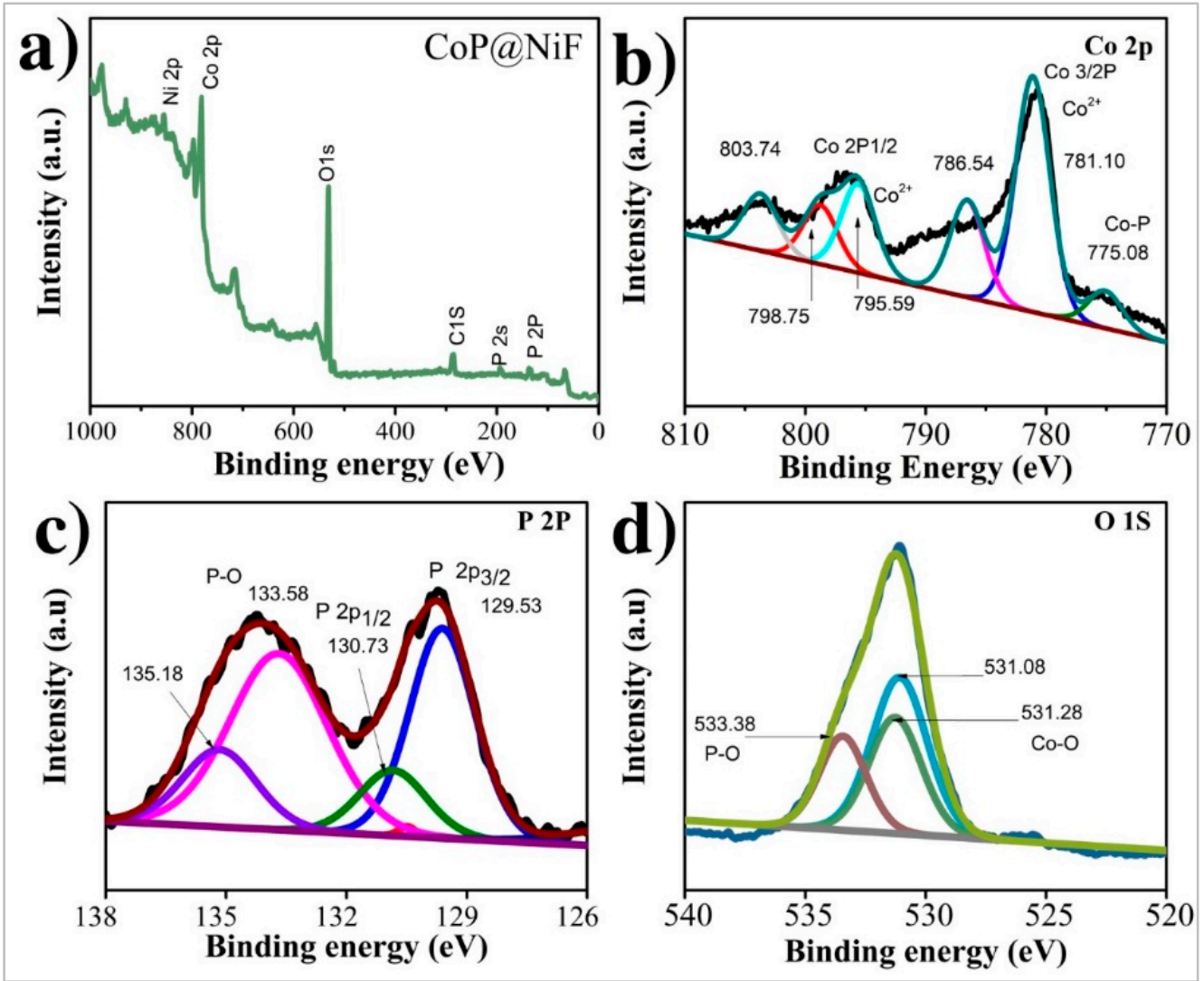

Figure 3. XPS spectra of CoP@NiF. (a) survey, (b) Co 2P, (c) P 2P and (d) O 1s.

Furthermore, compared to the binding energies of metallic Co $2 \mathrm{p}_{3 / 2}(778.1-778.2 \mathrm{eV})$ and elemental P $2 \mathrm{p}_{3 / 2}(130.2 \mathrm{eV})$, the peaks of Co $2 \mathrm{p}_{3 / 2}$ and $\mathrm{P} 2 \mathrm{p}_{3 / 2}$ have shifted positively and negatively. Revealing electron transfer from Co atoms to $\mathrm{P}$ atoms in CoP sheets, suggesting a partial positive charge for Co centers and a partial negative charge for $\mathrm{P}$ centers [33]. This type of charge transfer facilitates the adsorption and desorption of intermediates and products during electrochemical oxidation of various substrates $[34,35]$.

Cyclic Voltammetry (CV) studies were performed to examine the prepared electrode's catalytic activity for alcohol oxidation. For this approach, a three-electrode system cell was used in which bare nickel foam, platinum electrode, and $\mathrm{Ag} / \mathrm{AgCl}$ serve as the working, counter, and reference electrodes, respectively. The CV results indicate that after adding benzyl alcohol to the acetonitrile-water mixture solvent, the current density was increased significantly, which was attributed to the alcohol-oxidation reaction (Figure 4a). The same was observed with the addition of 2-phenoxyethanol in Figure 3b. However, 2-phenoxyethanol shows a lower current density increment compared to benzyl alcohol.

Furthermore, the addition of HMF also enhanced the current density. These findings show that the prepared $\mathrm{CoP}$ electrocatalyst exhibits significant catalytic activity towards the oxidation of alcohols. It is worth mentioning that the bare nickel foam showed lower current density and low capacitive current for all the substrates, as illustrated in Figure 4. Figure $3 \mathrm{~d}$ depicts a five-hour duration chronoamperometry curve for the CoP@NiF electrode in the presence of the electrolytes. No significant changes in current density were observed for the entire period investigated, demonstrating the chemical stability of the electrocatalyst under the applied experimental conditions. 

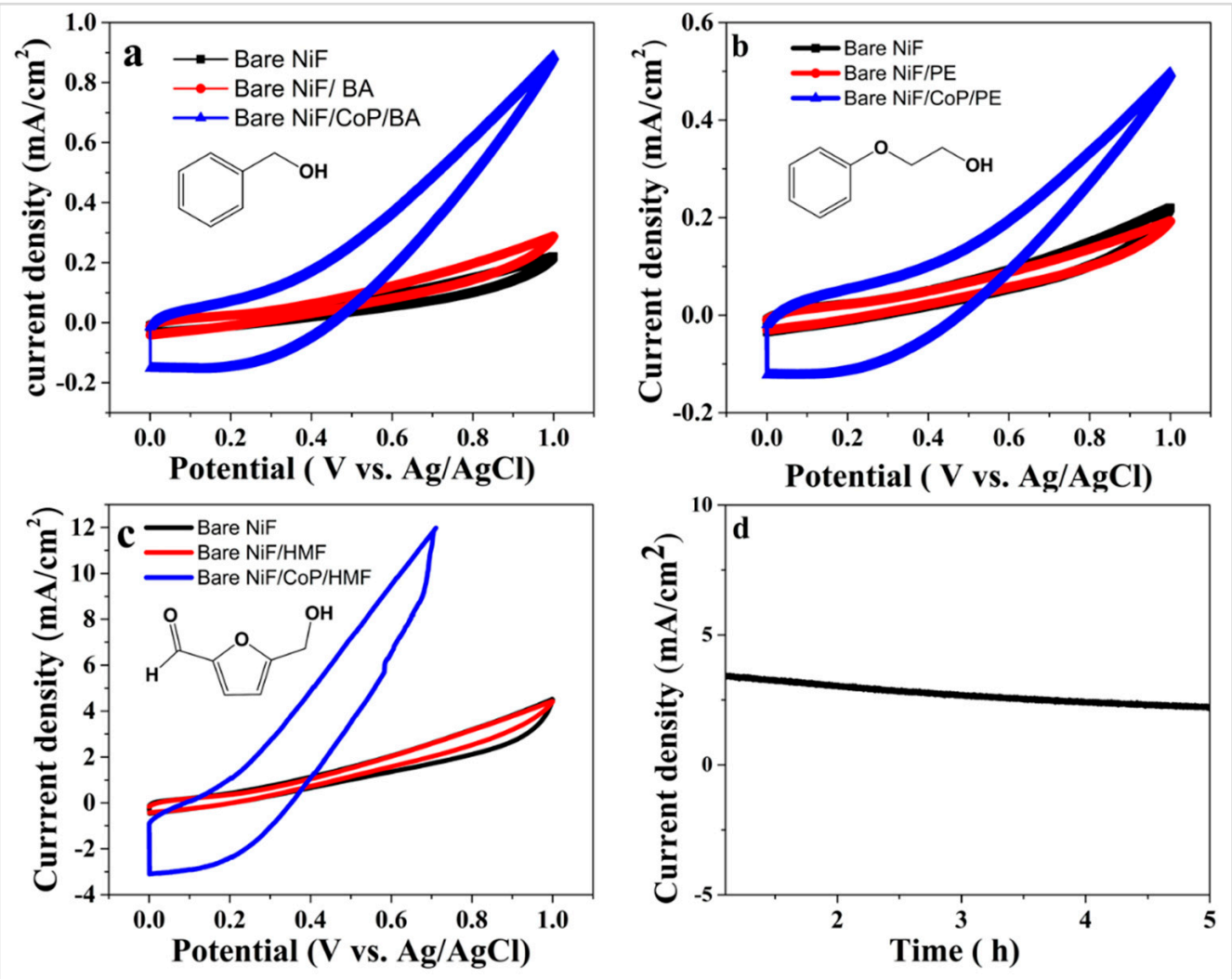

Figure 4. The CV of a different substrate of CoP@NiF electrocatalysts in 1.0 M KOH: (a) benzyl alcohol, (b) 2-phenoxyethanol, (c) HMF, (d) current-time curve of the CoP@NiF.

Our investigation of the reaction condition starts with benzyl alcohol (1a), which was initially exposed to a batch condition (no droplet flow) in an undivided cell (Table 1). This approach yielded a $47 \%$ selectivity for benzaldehyde (1b) after $1 \mathrm{~h}$ of electrolysis at $2.0 \mathrm{~V}$. A mixture of acetonitrile and water (1:1) was employed as a solvent to increase the starting material's solubility. The selectivity of generating benzaldehyde was achieved by employing a low concentration of potassium hydroxide, which reduced the possibility of the Cannizaro reaction.

Table 1. Optimization of droplet-assisted electrochemical oxidation of benzyl alcohol *.

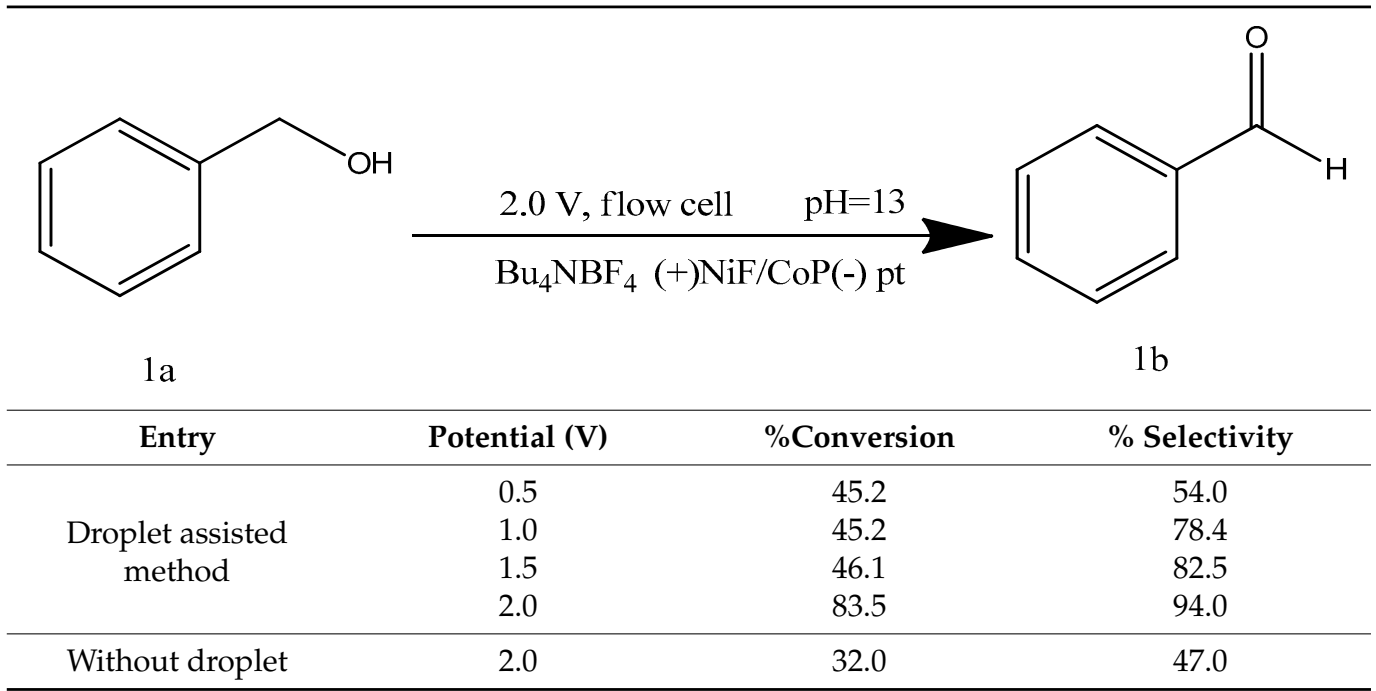

* Reaction conditions: Benzyl alcohol $(2.0 \mathrm{mmol})$ and $\mathrm{KOH}(0.01 \mathrm{M})$, the temperature at $25^{\circ} \mathrm{C}$, electrolysis time is $60 \mathrm{~min}$. The stirring rate is $250 \mathrm{rpm}$, and the flow rate is $12.5 \mu \mathrm{L} / \mathrm{min}$. 
The continuous electrochemical flow cell with a droplet flow mechanism was then used in the next phase. The selectivity of generating benzaldehyde with this method reached $94 \%$ for the same experimental conditions, whereas the (1a) selectivity was only $47.0 \%$. The increased conversion and product selectivity facilitated by the flow droplet mechanism was attributed to the enhanced surface reaction at the electrode interface. The effect of electrical potential variation on the conversion and selectively was also studied, as shown in Table 1. Although there was no change in the conversion of benzyl alcohol at lower potentials $(0.5-1.5 \mathrm{~V})$, the potential was discovered to impact the product selectivity significantly.

In the next stage, we investigated the transformation of 2-phenoxyethanol using the droplet flow-assisted electrochemical oxidation approach. According to reports, at a potential of $1.6 \mathrm{~V}$, the oxygen atom of a phenoxy molecule of 2-phenoxyethanol may be oxidized to generate a positively charged radical that can then be utilized to construct polymer chains. Its oxidation potential is approximately $1.0 \mathrm{~V}$ higher than that of most phenols. Based on these findings, we limit our voltage variation in this study to $1.6 \mathrm{~V}$ for 2-phenoxyethanol conversion. The experimental results are displayed in Table 2. In entry 1, a mixture of $\mathrm{CH}_{3} \mathrm{CN} / \mathrm{H}_{2} \mathrm{O}(1: 1)$ was used; only a $6.0 \%$ conversion was achieved. This lower conversion may be due to the insolubility of the substrate, so no electrochemical oxidation is expected to occur at this condition. Entry 2 involves a control experiment with the bare nickel foam without the electrocatalyst, which also shows a lower conversion of $8 \%$ for 2-phenoxyethanol and a selectivity of $12 \%$. In the case of entry 3 , when $\mathrm{NaOH}$ 1.0 $\mathrm{M}$ was used as a supporting electrolyte, $56.5 \%$ conversion of 2-phenoxyethanol was achieved (entry 3). In the former entry 4, the major products of this entry were phenol and formic acid with $92 \%$. According to the HPLC results, the major products of this reaction were phenol and formic acid. It is essential to keep in mind that the formation of formic acid increased over time, reaching its peak at $40 \mathrm{~min}$ of electrolysis and then immediately disappearing after $1.0 \mathrm{~h}$.

Table 2. Optimization of droplet-assisted electrochemical oxidation of 2-phenoxyethanol *.

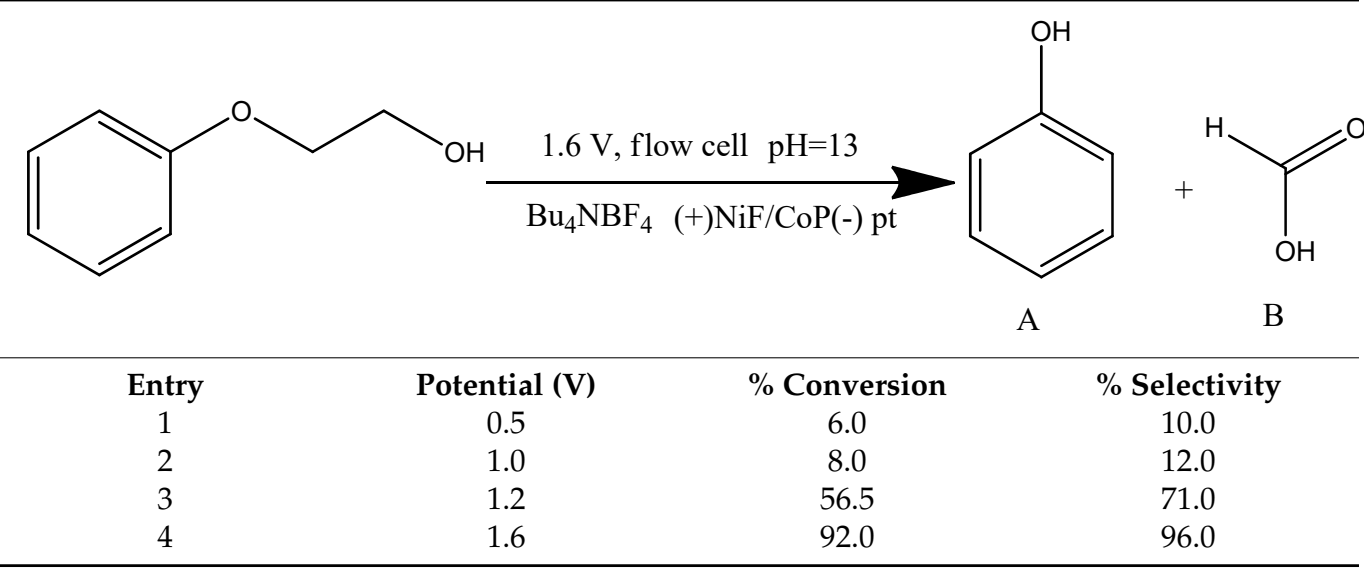

* Reaction conditions: Phenoxyethanol $(2.0 \mathrm{mmol}), \mathrm{NaOH}(1.0 \mathrm{M})[\mathrm{b}]$ determined by HPLC, temperature at $25^{\circ} \mathrm{C}$, electrolysis time is $60 \mathrm{~min}$. The stirring rate is $250 \mathrm{rpm}$, and the flow rate is $12.5 \mu \mathrm{L} / \mathrm{min}$.

Next, the conversion of HMF with droplet flow-assisted electrochemical oxidation was examined in an alkaline medium $(1.0 \mathrm{M} \mathrm{NaOH})$ in the presence of $20 \mathrm{mM}$ of HMF. Similar to the previous transformation experiment, the electrical potential was varied from 0.5 to $1.6 \mathrm{~V}$. Table 3 shows the conversion of HMF and the selectivity of the formed 2,5furandicarboxylic acid (FDCA) using the droplet flow electrochemical oxidation approach. As shown, the increase in potential from 0.5 and $0.7 \mathrm{~V}$ led to an increase in conversion and selectivity (entries 1 and 2). In contrast, entry 3 showed that the selectivity decreased as the voltage increased to $1.0 \mathrm{~V}$. Furthermore, high selectivity and high conversion were noted at high voltage, as shown in entries 4 and 5 . It is worth mentioning that at potentials greater 
than $1.3 \mathrm{~V}$, a slight decrease in the selectivity was observed, which could be attributed to product decomposition at the higher voltage. The optimum condition was $1.3 \mathrm{~V}$ for $1.0 \mathrm{~h}$ to get the high selectivity for FDCA, which was attributed to the enhancement from the droplet-assisted method. In comparison, a bath mode was applied, and the reaction took $2.0 \mathrm{~h}$ to achieve the same conversion and selectivity.

Table 3. Optimization of droplet assisted electrochemical oxidation of HMF *.

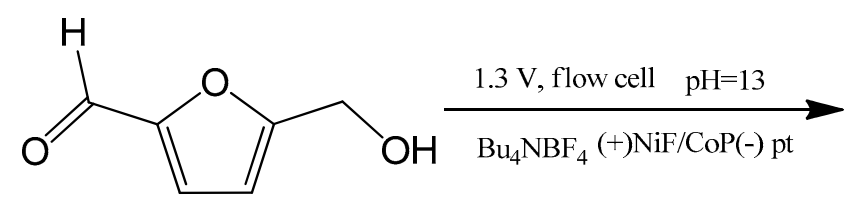

$\mathrm{HMF}$<smiles></smiles>

FDCA

\begin{tabular}{cccc}
\hline Entry & Potential (V) & \% Conversion & \% Selectivity \\
1 & 0.5 & 66.0 & 68.5 \\
2 & 0.7 & 88.0 & 91.6 \\
3 & 1.0 & 89.2 & 92.0 \\
4 & 1.3 & 95.0 & 96.0 \\
5 & 1.6 & 86.0 & 88.0 \\
\hline
\end{tabular}

${ }^{*}$ Reaction conditions: HMF $(20 \mathrm{mM})$ and $\mathrm{KOH}(1.0 \mathrm{M})$, the volume of electrolyte $(30 \mathrm{~mL}), 5 \mathrm{~mL}$ of HMF in the nebulizer box, and temperature at $25^{\circ} \mathrm{C}$ for $60 \mathrm{~min}$. The stirring rate is $250 \mathrm{rpm}$, and the flow rate is $12.5 \mu \mathrm{L} / \mathrm{min}$.

With the insight that CoP@NiF supported catalysts can drive the oxidation of various alcohols, the oxidation of BA, 2-PE, and HMF was investigated at room temperature and atmospheric pressure. Figure 4 depicts the decrease in alcohol concentration and the formation of aldehyde as a function of reaction time. It is clear that the formation of benzaldehyde occurred even within the first $10 \mathrm{~min}$. The concentration of benzaldehyde increased dramatically as the reaction progressed. It is worth noting that no significant benzoic acid was detected in the reaction medium, indicating that the electrode has a high selectivity to produce only benzaldehyde. However, as shown in Figure $4 b$, the change in 2-PE concentration over time revealed two main products: phenol and acetic acid.

On the other hand, HMF oxidation produced intermediate and interstitially high yields of FDCA in a short time. The reaction had reached $60 \%$ FDCA formation after $30 \mathrm{~min}$. The fast conversion indicates that the main difference between microdroplets and bulk solutions is the large surface area and confined space of the droplet on all different substrates [24].

The ability to recycle an electrode is a critical factor in determining electrode stability. The recyclability of the CoP@NiF electrode was investigated by electrolyzing it several times. As shown, the CoP@NiF is an efficient, recyclable electrocatalyst for the selective electrochemical oxidation of BA, 2-PE, and HMF substrates. The electrochemical oxidation of the substrates as a function of different runs is illustrated in Figure $5 \mathrm{~d}$. Table 4 compares our present work to previous work in the literature, and it demonstrates fast and high conversion that is superior to the published literature. 

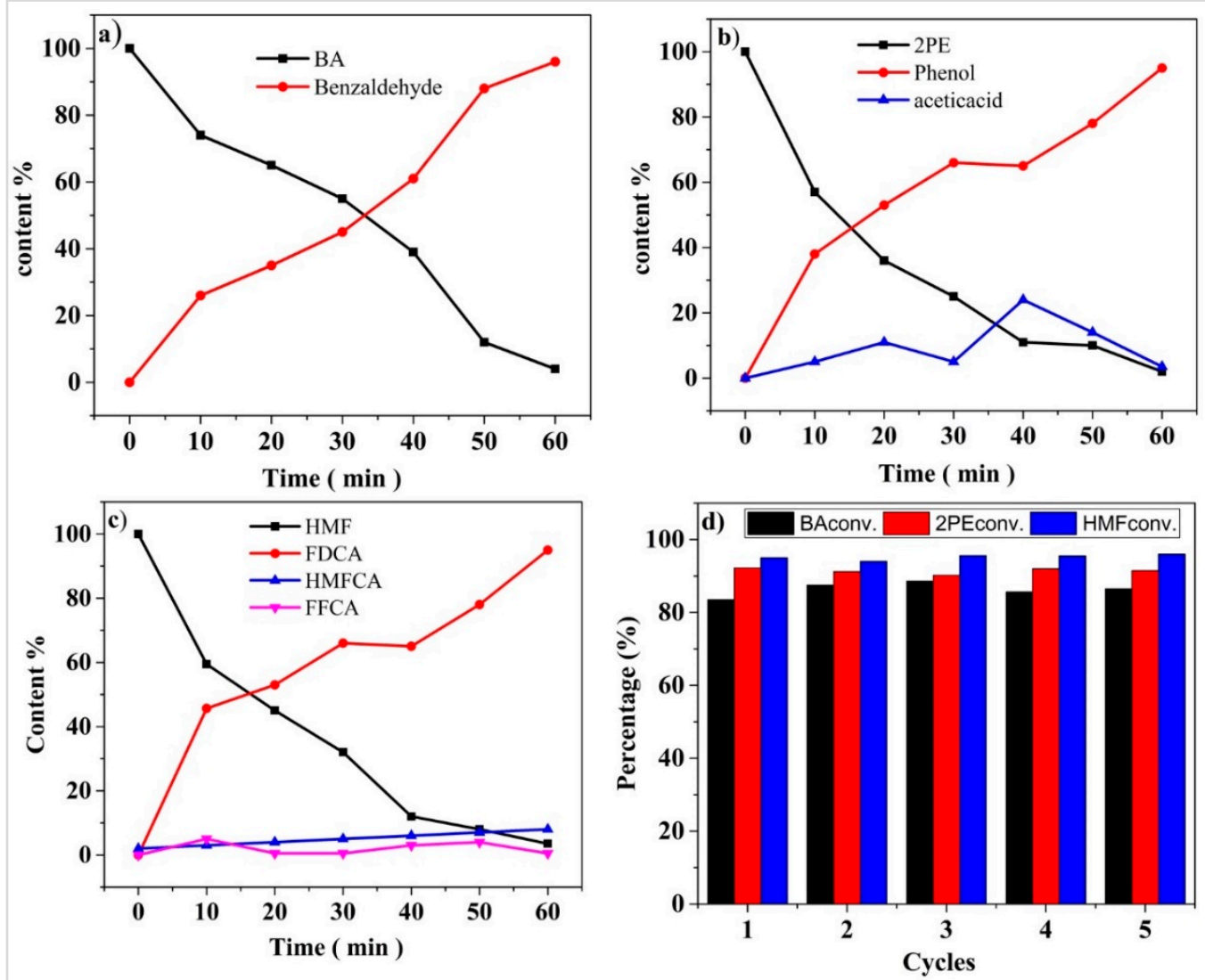

Figure 5. Evolution of reactant substrate and product concentrations for (a) BA, (b) 2-PE, and (c) HMF. (d) Effect of recycling on the electrocatalytic oxidation of CoP@NiF for the conversion of different substrates.

Table 4. Comparison of electrochemical oxidation of alcohol using various electrocatalyst.

\begin{tabular}{|c|c|c|c|c|c|c|c|}
\hline Catalyst & Substrate & Product & Conv. $\%$ & Yield \% & Condition & $\begin{array}{l}\text { Time } \\
(\mathrm{min})\end{array}$ & Ref. \\
\hline Nickel oxy-hydroxide electrode & $\mathrm{BA}\left({ }^{*}\right)$ & $\begin{array}{l}\text { Benzaldehyde, } \\
\text { Benzoic acid }\end{array}$ & - & $86 \%$ & $0.01 \mathrm{M} \mathrm{NaOH}$ & 300 & {$[36]$} \\
\hline $\begin{array}{c}\text { Au NP- modified } \\
\text { carbon-fiber-thread electrode }\end{array}$ & $\begin{array}{c}\mathrm{BA} \\
1-\mathrm{PE}\end{array}$ & $\begin{array}{l}\text { Benzaldehyde } \\
\text { Acetophenone }\end{array}$ & $\begin{array}{l}- \\
-\end{array}$ & $\begin{array}{l}50-55 \\
38-65\end{array}$ & $\begin{array}{c}\mathrm{KOH}, \mathrm{LiClO}_{4}[\mathrm{a}] \\
\mathrm{KOH}, \mathrm{LiClO}_{4}\end{array}$ & - & [7] \\
\hline $\begin{array}{l}\text { TEMPO }(0.1 \mathrm{mmol}) \\
\text { NHPI }(0.1 \mathrm{mmol})\end{array}$ & $\begin{array}{l}\text { BA } \\
\text { BA }\end{array}$ & $\begin{array}{l}\text { Benzaldehyde } \\
\text { Benzaldehyde }\end{array}$ & $\begin{array}{l}92.0 \\
57.0\end{array}$ & - & $\begin{array}{l}\text { Carbonate buffer } \\
\text { Acetate buffer }\end{array}$ & 120 & [37] \\
\hline Co-P on $\mathrm{Cu}$ foam & HMF & FDCA & 99.0 & 85.3 & $\begin{array}{l}\text { Deep eutectic solvents, } \\
0.5 \mathrm{M} \mathrm{NaHCO}_{3}\end{array}$ & - & [38] \\
\hline Carbon anode & BA & Benzaldehyde & - & 95.0 & $\begin{array}{l}\text { Undivided, } 30-34^{\circ} \mathrm{C} \mathrm{HCl} \\
\text { as supporting electrolyte } \\
\text { nitrate as mediator }\end{array}$ & - & [39] \\
\hline $\mathrm{CoP@NiF}$ & $\begin{array}{l}\text { BA } \\
2-\mathrm{PE} \\
\mathrm{HMF}\end{array}$ & $\begin{array}{c}\text { Benzoic acid } \\
\text { Phenol \& } \mathrm{CH}_{3} \mathrm{CO}_{2} \mathrm{H} \\
\text { FDCA }\end{array}$ & $\begin{array}{l}95.0 \\
96.0 \\
95.0\end{array}$ & $\begin{array}{l}96.0 \\
96.0 \\
96.0\end{array}$ & Droplet assisted method & 60 & This work \\
\hline
\end{tabular}

(*) BA, benzyl alcohol; TEMPO: (2,2,6,6-tetrame- thylpiperidin-1-yl)oxyl, (NHPI) N-hydroxyphthalimide, 2-PE (2-phenoxyethanol).

\section{Materials and Methods}

\subsection{Chemicals}

Cobalt (II) chloride hexahydrate $\left(\mathrm{CoCl}_{2} \cdot 6 \mathrm{H}_{2} \mathrm{O}\right)$, sodium dihydrogen phosphate $\left(\mathrm{NaH}_{2} \mathrm{PO}_{4}\right)$, potassium chloride, nickel foam, benzyl alcohol (BA), 2-phenoxyethanol (2$\mathrm{PE})$, hydroxymethylfurfural (HMF), potassium hydroxide $(\mathrm{KOH})$, ammonium formate, tetrabutylammonium tetrafluoroborate $\left(\mathrm{Bu}_{4} \mathrm{NBF}_{4}\right)$, and acetonitrile. All reagents were purchased from Sigma Aldrich and used without any further purification. 


\subsection{Synthesis of CoP@Ni Foam}

The CoP was deposited on the nickel foam by using the electrodeposition method. In brief, cobalt chloride hexahydrate $\left(\mathrm{CoCl}_{2} \cdot 6 \mathrm{H}_{2} \mathrm{O}\right)$ and sodium dihydrogen phosphate $\left(\mathrm{NaH}_{2} \mathrm{PO}_{4}\right)$ were used as cobalt and phosphorus sources, respectively. A supporting electrolyte of $\mathrm{KCl}$ was dissolved in a specific volume of deionized water under nitrogen gas purging. The electrodeposition of CoP film was performed by using a standard threeelectrode system: the working electrode was cleaned bare $\mathrm{NiF}$, the counter electrode was platinum, and the reference electrode was silver/silver. Then, the applied potential of $-1.0 \mathrm{~V}$ was polarized into the Ni foam surface. Finally, the working electrode was rinsed with deionized water and dried at room temperature after the electrodeposition. The method of synthesis is shown in Scheme 1.

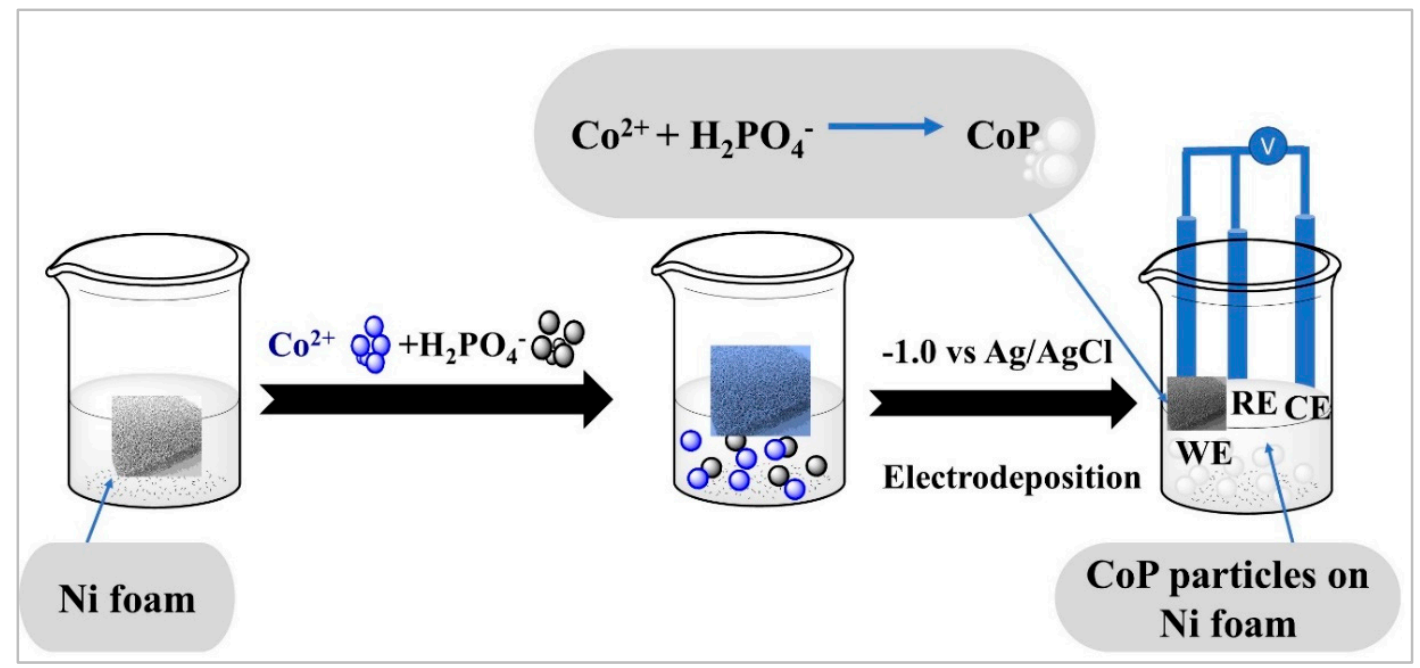

Scheme 1. Schematic diagram of CoP@NiF synthesis.

\subsection{Structural Characterization}

The surface characterization of the prepared CoP@NiF electrode was performed using field emission scan electron microscopy (FE-SEM) coupled with energy-dispersive X-ray spectroscopy (EDS). An X-ray photoelectron spectrometer was used to collect the surface elemental composition (Thermo Scientific ESCALAB 250Xi, Waltham, MA, USA). The C1s hydrocarbon peak at $284.60 \mathrm{eV}$ was used to calibrate all binding energies.

\subsection{Droplet-Assisted Electrochemical Oxidation of Alcohols}

All electrochemical experiments were carried out using $\mathrm{CH}$ Instruments $1140 \mathrm{~A}$ potentiostats (CH Instruments, Inc., Austin, TX, USA). An undivided electrochemical cell (EuroCell) with a $50 \mathrm{~mL}$ volume (working solution, $0.21 \mathrm{~L}$ and GSG-ME) was modified to suit a droplet-flow assisted configuration. Scheme 2 shows the schematic diagram of the droplet-assisted electrochemical flow reactor used in this work. A nickel foam was used as the anode, while the cathode was a platinum electrode and was connected to a direct current power source (Ealing High voltage power supply, 0-50 V). The electrodes were placed $1.5 \mathrm{~cm}$ from the reactor's bottom and $2.0 \mathrm{~cm}$ apart as an inter-electrode gap. An air pump connected to the sample flow recirculatory system was used to create a nebulized mist of the sample solution directed at the anode surface.

For all the experiments, the bulk sample solutions were stirred magnetically. The electrochemical droplet assisted condition setup was set $\mathrm{CoPNiF}$ as the anode, and the $\mathrm{Pt}$ electrode was used as the cathode. A mixture of $30 \mathrm{~mL}$ of acetonitrile and $\mathrm{H}_{2} \mathrm{O}(1: 1)$ as supporting electrode and $0.2 \mathrm{mmol}$ of $\mathrm{Bu}_{4} \mathrm{NBF}_{4}$. The concentration of the different alcohol substrates was $2.0 \mathrm{mmol}$. All the experimental electrolysis was repeated three times. 


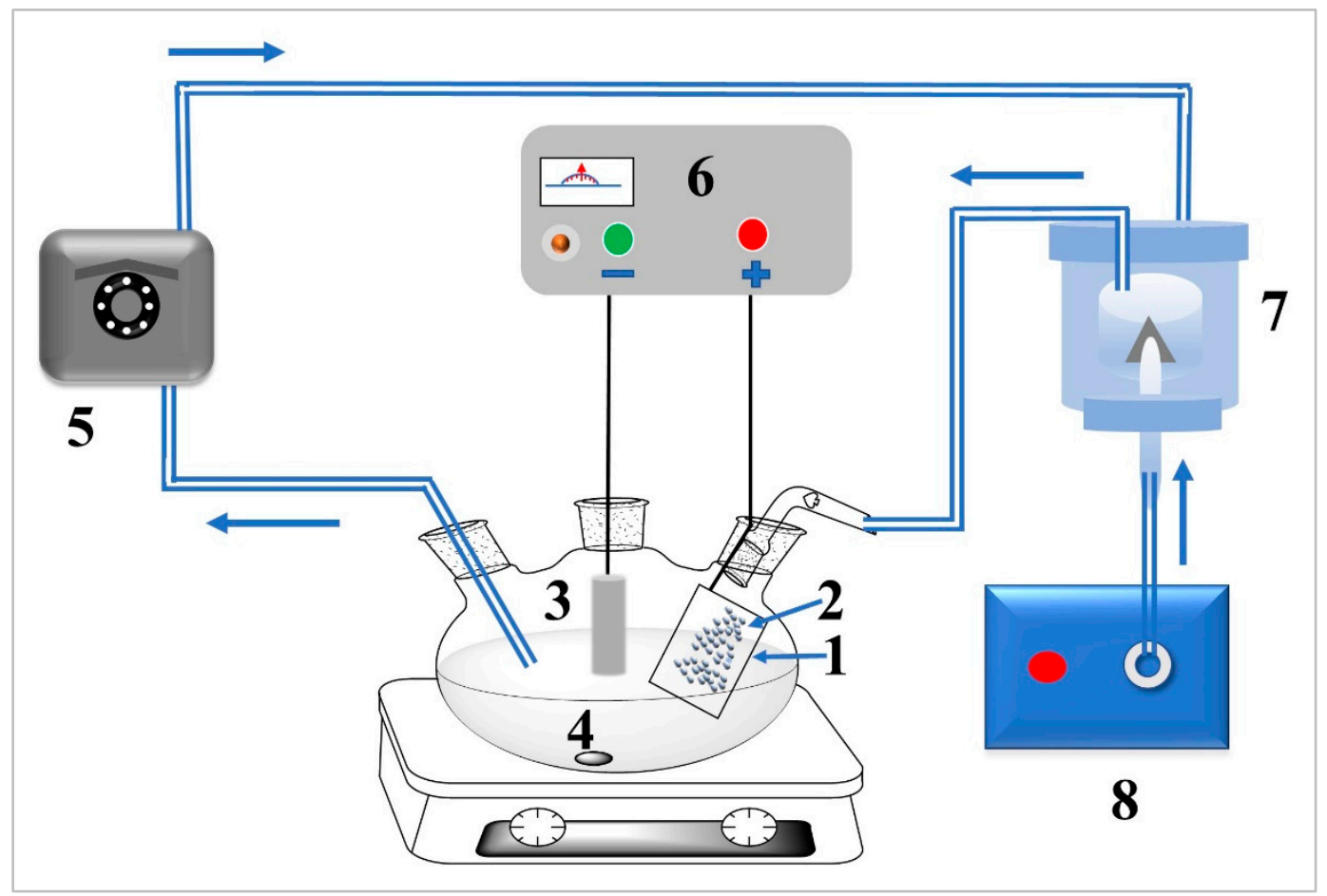

Scheme 2. The experimental setup of the droplet assisted electrosynthesis reactor includes: (1) CoP@NiF (the anode), (2) droplet formation, (3) platinum electrode acting as the cathode, (4) magnetic stirrer, (5) peristaltic pump, (6) DC power supply, (7) nebulizer junction for mixing natural air with the untreated sample to form a droplet spray at the anode surface, and (8) air pump.

\subsection{Liquid Chromatography Analysis}

High-performance liquid chromatography (HPLC, Shimadzu) was used in monitoring the electrochemical oxidation process. Data acquisition and quantification are conducted with Lab Solutions, LC Ver.5.91, Shimadzu. An autosampler-CTC-Pal (Analytics, NC, USA) ultra IBD column $(100 \times 2.1 \mathrm{~mm} \times 3 \mu \mathrm{m}$ particle size; Restek, PA, USA $)$ was used for the separation of target analytes. Isocratic elution using solvent $\mathrm{A}$ ( $5.0 \mathrm{mM}$ ammonium formate) and solvent $\mathrm{B}$ (acetonitrile) was applied at a flow rate of $0.04 \mathrm{~mL} / \mathrm{min}$. The injection volume was $2.0 \mu \mathrm{L}$ with the isobaric condition.

Standard solutions of reactants and products, such as benzyl alcohol, 2-phenoxyethanol, and HMF, were used to obtain the calibration curves. The alcohol concentrations and their oxidation products were determined from the peak areas. Percent (\%) conversion and selectivity were calculated using the following formulas:

$$
\begin{aligned}
& \text { Conversion } \%=\frac{\left(\mathrm{C}_{\mathrm{r}_{0}}-\mathrm{C}_{\mathrm{r}}\right)}{\mathrm{C}_{\mathrm{r}_{0}}} * 100 \\
& \text { Selectivity }=\frac{\mathrm{C}_{\mathrm{p}}}{\left(\mathrm{C}_{\mathrm{r}_{0}}-\mathrm{C}_{\mathrm{r}}\right)} * 100
\end{aligned}
$$

$\mathrm{C}_{\mathrm{r}_{0}}$ denotes the reactant's initial concentration, $\mathrm{C}_{\mathrm{r}}$ and $\mathrm{C}_{\mathrm{p}}$ denote reactant's and product's concentration during the reaction, respectively [40].

\section{Conclusions}

To conclude, a fast and straightforward transformation of alcohols and HMF into the corresponding intermediates using droplet assisted flow with a continuous flow electrochemical reactor was demonstrated for the first time. The selectivity and yield of benzaldehyde can be tuned by electrolysis potential. The results show that at $1.5 \mathrm{~V}$ and $318.15 \mathrm{~K}$, both the selectivity and the yield of benzaldehyde can reach above $98.8 \%$ with the 
system under ambient conditions. An accelerated droplet synthesis approach of alcohol and its derivatives has been achieved.

Author Contributions: Conducted experiment, M.A.S.; Conceptualization and designed the experiment and supervised C.B.; Preparing the electrode material, K.M.A.A. All authors equally participated in writing the manuscript. All authors have read and agreed to the published version of the manuscript.

Funding: The authors acknowledge the funding support of the deanship of scientific research to support this work at King Fahd University of Petroleum and Minerals through project no DSRDF181012.

Institutional Review Board Statement: Not applicable.

Informed Consent Statement: Not applicable.

Data Availability Statement: Data is contained within the article.

Acknowledgments: Authors would like to acknowledge the support of the Chemistry department, King Fahd University of Petroleum and Minerals (KFUPM), in carrying out this work.

Conflicts of Interest: The authors declare no conflict of interest.

\section{References}

1. Yuan, Y.; Lei, A. Is electrosynthesis always green and advantageous compared to traditional methods? Nat. Commun. 2020, 11, 2018-2020. [CrossRef]

2. $\quad$ Rafiee, M.; Konz, Z.M.; Graaf, M.D.; Koolman, H.F.; Stahl, S.S. Electrochemical oxidation of alcohols and aldehydes to carboxylic acids catalyzed by 4-acetamido-TEMPO: An alternative to "anelli" and "pinnick" oxidations. ACS Catal. 2018, 8, 6738-6744. [CrossRef]

3. Carbonio, E.A.; Nagao, R.; Gonzalez, E.R.; Varela, H. Temperature effects on the oscillatory electro-oxidation of methanol on platinum. Phys. Chem. Chem. Phys. 2009, 11, 665-670. [CrossRef]

4. Miyamura, H.; Matsubara, R.; Miyazaki, Y.; Kobayashi, S. Aerobic oxidation of alcohols at room temperature and atmospheric conditions catalyzed by reusable gold nanoclusters stabilized by the benzene rings of polystyrene derivatives. Angew. Chem.-Int. Ed. 2007, 46, 4151-4154. [CrossRef]

5. Jia, A.; Lou, L.L.; Zhang, C.; Zhang, Y.; Liu, S. Selective oxidation of benzyl alcohol to benzaldehyde with hydrogen peroxide over alkali-treated ZSM-5 zeolite catalysts. J. Mol. Catal. A Chem. 2009, 306, 123-129. [CrossRef]

6. Wang, D.; Wang, P.; Wang, S.; Chen, Y.H.; Zhang, H.; Lei, A. Direct electrochemical oxidation of alcohols with hydrogen evolution in continuous-flow reactor. Nat. Commun. 2019, 10, 2796. [CrossRef] [PubMed]

7. Suga, T.; Shida, N.; Atobe, M. Au-catalyzed electrochemical oxidation of alcohols using an electrochemical column flow cell Electrochem. Commun. 2021, 124, 106944. [CrossRef]

8. Bender, M.T.; Lam, Y.C.; Hammes-Schiffer, S.; Choi, K.S. Unraveling two pathways for electrochemical alcohol and aldehyde oxidation on NiOOH. J. Am. Chem. Soc. 2020, 142, 21538-21547. [CrossRef] [PubMed]

9. Yan, X.; Bain, R.M.; Cooks, R.G. Organic reactions in microdroplets: Reaction acceleration revealed by mass spectrometry. Angew. Chem.-Int. Ed. 2016, 55, 12960-12972. [CrossRef] [PubMed]

10. Mondal, S.; Subhajit, A.; Rajib, B.; Biman, B.; Richard, N.Z. Enhancement of reaction rate in small-sized droplets: A combined analytical and simulation study. J. Chem. Phys. 2018, 148, 244704. [CrossRef] [PubMed]

11. Zhang, Y.; Apsokardu, M.J.; Kerecman, D.E.; Achtenhagen, M.; Johnston, M.V. Reaction kinetics of organic aerosol studied by droplet assisted ionization: Enhanced reactivity in droplets relative to bulk solution. J. Am. Soc. Mass Spectrom. 2020, 32, 46-54. [CrossRef]

12. Wei, Z.; Li, Y.; Cooks, R.G.; Yan, X. Accelerated reaction kinetics in microdroplets: Overview and recent developments. Annu. Rev. Phys. Chem. 2020, 71, 31-51. [CrossRef] [PubMed]

13. Fallah-Araghi, A.; Meguellati, K.; Baret, J.C.; El Harrak, A.; Mangeat, T.; Karplus, M.; Ladame, S.; Marques, C.M.; Griffiths, A.D. Enhanced chemical synthesis at soft interfaces: A universal reaction-adsorption mechanism in microcompartments. Phys. Rev. Lett. 2014, 112, 028301. [CrossRef] [PubMed]

14. Sahota, N.; Abusalim, D.I.; Wang, M.L.; Brown, C.J.; Zhang, Z.; El-Baba, T.J.; Cook, S.P.; Clemmer, D.E. A microdroplet-accelerated Biginelli reaction: Mechanisms and separation of isomers using IMS-MS. Chem. Sci. 2019, 10, 4822-4827. [CrossRef] [PubMed]

15. Li, Y.; Mehari, T.F.; Wei, Z.; Liu, Y.; Cooks, R.G. Reaction acceleration at air-solution interfaces: Anisotropic rate constants for Katritzky transamination. J. Mass Spectrom. 2021, 56, e4585. [CrossRef] [PubMed]

16. Cao, J.; Wang, Q.Q.; An, S.Q.; Lu, S.F.; Jia, Q.Z. Facile and efficient preparation of organoimido derivatives of $\left[\mathrm{Mo}_{6} \mathrm{O}_{19}\right]_{2}-\mathrm{using}$ accelerated reactions in Leidenfrost droplets. Analyst 2020, 145, 4844-4851. [CrossRef] [PubMed]

17. Vaitheeswaran, S.; Thirumalai, D. Hydrophobic and ionic interactions in nanosized water droplets. J. Am. Chem. Soc. 2006, 128, 13490-13496. [CrossRef] 
18. Girod, M.; Moyano, E.; Campbell, D.I.; Cooks, R.G. Accelerated bimolecular reactions in microdroplets studied by desorption electrospray ionization mass spectrometry. Chem. Sci. 2011, 2, 501-510. [CrossRef]

19. Banerjee, S.; Zare, R.N. Syntheses of isoquinoline and substituted quinolines in charged microdroplets. Angew. Chem.-Int. Ed. 2015, 54, 14795-14799. [CrossRef]

20. Nam, I.; Lee, J.K.; Nam, H.G.; Zare, R.N. Abiotic production of sugar phosphates and uridine ribonucleoside in aqueous microdroplets. Proc. Natl. Acad. Sci. USA 2017, 114, 12396-12400. [CrossRef]

21. Nam, I.; Nam, H.G.; Zare, R.N. Abiotic synthesis of purine and pyrimidine ribonucleosides in aqueous microdroplets. Proc. Natl. Acad. Sci. USA 2018, 115, 36-40. [CrossRef]

22. Zhou, Z.; Yan, X.; Lai, Y.H.; Zare, R.N. Fluorescence polarization anisotropy in microdroplets. J. Phys. Chem. Lett. 2018, 9, 2928-2932. [CrossRef]

23. Narendra, N.; Chen, X.; Wang, J.; Charles, J.; Cooks, R.G.; Kubis, T. Quantum mechanical modeling of reaction rate acceleration in microdroplets. J. Phys. Chem. A. 2020, 124, 4984-4989. [CrossRef] [PubMed]

24. Basuri, P.; Gonzalez, L.E.; Morato, N.M.; Pradeep, T.; Cooks, R.G. Accelerated microdroplet synthesis of benzimidazoles by nucleophilic addition to protonated carboxylic acids. Chem. Sci. 2020, 11, 12686-12694. [CrossRef] [PubMed]

25. Barwe, S.; Weidner, J.; Cychy, S.; Morales, D.M.; Dieckhöfer, S.; Hiltrop, D.; Masa, J.; Muhler, M.; Schuhmann, W. Electrocatalytic oxidation of 5-(Hydroxymethyl)furfural using high-surface-area nickel boride. Angew. Chem.-Int. Ed. 2018, 57, 11460-11464. [CrossRef] [PubMed]

26. Zhong, D.K.; Gamelin, D.R. Photo-electrochemical water oxidation by cobalt catalyst ("Co-Pi")/ $\alpha-\mathrm{Fe}_{2} \mathrm{O}_{3}$ composite photoanodes: Oxygen evolution and resolution of a kinetic bottleneck. J. Am. Chem. Soc. 2010, 132, 4202-4207. [CrossRef]

27. Cabán-Acevedo, M.; Stone, M.L.; Schmidt, J.R.; Thomas, J.G.; Ding, Q.; Chang, H.C.; Tsai, M.L.; He, H.; Jin, S. Efficient hydrogen evolution catalysis using ternary pyrite-type cobalt phosphosulphide. Nat. Mater. 2015, 14, 1245-1251. [CrossRef] [PubMed]

28. Li, X.; Elshahawy, A.M.; Guan, C.; Wang, J. Metal phosphides and phosphates-based electrodes for electrochemical supercapacitors. Small 2017, 13, 1310-1319. [CrossRef] [PubMed]

29. Zhu, Y.P.; Liu, Y.P.; Ren, T.Z.; Yuan, Z.Y. Self-supported cobalt phosphide mesoporous nanorod arrays: A flexible and bifunctional electrode for highly active electrocatalytic water reduction and oxidation. Adv. Funct. Mater. 2015, 25, 7337-7347. [CrossRef]

30. Wang, H.; Gao, C.; Li, R.; Peng, Z.; Yang, J.; Gao, J.; Yang, Y.; Li, S.; Li, B.; Liu, Z. Ruthenium-cobalt nanoalloy embedded within hollow carbon spheres as a bifunctionally robust catalyst for hydrogen generation from water splitting and ammonia borane hydrolysis. ACS Sustain. Chem. Eng. 2019, 7, 18744-18752. [CrossRef]

31. Chang, J.; Xiao, Y.; Xiao, M.; Ge, J.; Liu, C.; Xing, W. Surface oxidized cobalt-phosphide nanorods as an advanced oxygen Evolution Catalyst in Alkaline Solution. ACS Catal. 2015, 5, 6874-6878. [CrossRef]

32. Roy, S.B.; Truong, L.; Jeon, J.H.; Lee, S.; Jerng, S.K.; Jung, E.; Chan Jun, S.; Chun, S.H. Highly desirable platform for efficient hydrogen generation: Electrodeposited CoP on N-doped vertical grapheme. ACS Appl. Energy Mater. 2021, 4, $5697-5705$. [CrossRef]

33. Burns, A.W.; Layman, K.A.; Bale, D.H.; Bussell, M.E. Understanding the relationship between composition and hydrodesulfurization properties for cobalt phosphide catalysts. Appl. Catal. A Gen. 2008, 343, 68-76. [CrossRef]

34. Rafai, S.; Qiao, C.; Wang, Z.; Cao, C.; Mahmood, T.; Naveed, M.; Younas, W.; Khalid, S. Cobalt phosphide ultrathin and freestanding Sheets prepared through microwave chemical vapor deposition: A highly efficient oxygen evolution reaction catalyst. ChemElectroChem 2019, 6, 5469-5478. [CrossRef]

35. Liu, M.; Li, J. Cobalt phosphide hollow polyhedron as efficient bifunctional electrocatalysts for the evolution reaction of hydrogen and oxygen. ACS Appl. Mater. Interfaces 2016, 8, 2158-2165. [CrossRef] [PubMed]

36. Motheo, A.J.; Tremiliosi-Filho, G.; Gonzalez, E.R.; Kokoh, K.B.; Léger, J.M.; Lamy, C. Electrooxidation of benzyl alcohol and benzaldehyde on a nickel oxy-hydroxide electrode in a filter-press type cell. J. Appl. Electrochem. 2006, 36, 1035-1041. [CrossRef]

37. Rafiee, M.; Karimi, B.; Alizadeh, S. Mechanistic study of the electrocatalytic oxidation of alcohols by TEMPO and NHPI. ChemElectroChem 2014, 1, 455-462. [CrossRef]

38. Kang, M.J.; Yu, H.J.; Kim, H.S.; Cha, H.G. Deep eutectic solvent stabilised Co-P films for electrocatalytic oxidation of 5hydroxymethylfurfural into 2,5-furandicarboxylic acid. New J. Chem. 2020, 44, 14239-14245. [CrossRef]

39. Christopher, C.; Lawrence, S.; Bosco, A.J.; Xavier, N.; Raja, S. Selective oxidation of benzyl alcohol by two phase electrolysis using nitrate as mediator. Catal. Sci. Technol. 2012, 2, 824-827. [CrossRef]

40. Qamar, M.; Elsayed, R.B.; Alhooshani, K.R.; Ahmed, M.I.; Bahnemann, D.W. Highly efficient and selective oxidation of aromatic alcohols photocatalyzed by nanoporous hierarchical $\mathrm{Pt} / \mathrm{Bi}_{2} \mathrm{WO}_{6}$ in organic solvent-free environment. ACS Appl. Mater. Interfaces 2015, 7, 1257-1269. [CrossRef] [PubMed] 